D. W. Dickson

\begin{abstract}
Progressive supranuclear palsy (PSP) and corticobasal degeneration (CBD) are usually sporadic multisystem degenerations associated with filamentous tau inclusions in neurons and glia. As such they can be considered sporadic tauopathies in contrast to familial tauopathies linked to mutations in the tau gene. Mutations have not been found in the tau gene in either PSP or CBD. The clinical syndromes and neuroimaging of typical cases of PSP and CBD are distinct; however,
\end{abstract}

Dennis W. Dickson, MD (凶)

Department of Pathology

Mayo Clinic Jacksonville

4500 San Pablo Road

Jacksonville, FL 32224, USA

Email: dickson.dennis@mayo.edu

\title{
Neuropathologic differentiation of progressive supranuclear palsy and corticobasal degeneration
}

atypical cases are described that have overlapping clinical and pathologic features. Both PSP and CBD have similar biochemical alterations in the tau protein, with the abnormal tau protein containing predominantly four-repeat tau. While there is overlap in the pathology in PSP and CBD, there are sufficient differences to continue the present day trend to consider these separate disorders. Several important pathologic features differentiate PSP from CBD. Ballooned neurons are frequent and nearly a sine qua non for CBD, but they are found in PSP at a frequency similar to that of other neurodegenerative diseases, such as Alzheimer's disease. Astrocytic lesions are different, with tufted astrocytes found in motor cortex and striatum in PSP and astrocytic plaques in focal atrophic cortices in CBD. The most characteristic neuronal tau pathology in CBD is wispy, fine filamentous inclusions within neuronal cell bodies, while affected neurons in PSP have compact, dense filamentous aggregates characteristic of globose neurofibrillary tangles. Thread-like processes in gray and white matter are much more numerous and widespread in CBD than in PSP. The brunt of the pathology in CBD is in the cerebrum, while the basal ganglia, diencephalon and brainstem are the targets of PSP. Further clinicopathologic studies will refine our understanding of these disorders and open the possibility that common etiologic factors may be identified for these unusual sporadic tauopathies.

Key words Corticobasal degeneration . Progressive supranuclear palsy · Tau . Neuropathology

\section{Introduction}

Progressive supranuclear palsy (PSP) is a multisystem degeneration characterized by neurofibrillary tangles (NFT) in the affected cell populations. It is one of the major causes of levodopa-nonresponsive Parkinsonism [67]. Many early cases of PSP present with unexplained falls and only later in the course does the characteristic clinical picture emerge, which features postural instability, vertical gaze palsy, axial rigidity, dysarthria and dementia [37]. PSP is an uncommon disorder, with prevalence rate estimates of about 1.5 per 100,000 [36], compared to 100 to 150 per 100,000 for Parkinson's disease
(PD). New cases occur at a rate of about 3 to 4 per million population per year [67].

Corticobasal degeneration (CBD) was first described in 1967 by Rebeiz as "corticodentatonigral degeneration with neuronal achromasia" [68]. While prevalence rates have not been estimated for CBD, it is less common than PSP. True prevalence rates would be difficult to estimate since the clinical and pathological spectrum of CBD is currently being refined, as evident in a number of recent clinicopathologic reports [54]. Original descriptions emphasized early and prominent asymmetrical movement disorder, but more recent reports have indicated that individuals with postmortem 
findings of CBD may also have focal cortical syndromes, such as frontal lobe dementia or progressive aphasia [35, 54, 64]. This would suggest that the clinical phenotype of CBD is a reflection of the location of the dominant cortical pathology with the classical phenotype corresponding to damage to the paracentral and superior frontal and parietal cortex. In cases with language abnormalities the brunt of the pathology is in the peri-Sylvian region.

\section{Clinical differentiation of PSP and CBD}

While not the primary focus of this presentation, a few words on the clinical features of PSP and CBD are warranted as a prelude to discussion of the differentiation of the two disorders pathologically. The most common initial sign of PSP is postural instability leading to falls and gait disturbance. [37]. Gait problems are progressive and disabling, leading eventually to confinement to chair or bed. CBD has a distinctly different presentation in typical cases. The initial signs are unilateral or asymmetrical apraxia, rigidity and dystonia. This may be associated with myoclonic jerks, grasp reflex, cortical sensory impairment and alien limb phenomenon. The affected hand may develop dystonic flexion contractures. Bradykinesia, rigidity, loss of facial expression, difficulty turning in bed or rising from a chair, loss of arm swing and reduced stride length that bring to consideration PD may be seen in both CBD and PSP; however, neither PSP nor CBD typically have a sustained clinical response to levodopa treatment.

Eye movement abnormalities are the hallmark of PSP and are characterized initially by impairment of downgaze, which is eventually followed by difficulties with upgaze and even horizontal gaze. There is usually striking preservation of the oculocephalic reflexes [37]. A supranuclear down-gaze palsy may develop in the course of CBD, but it is not usually as prominent as in PSP. These atypical cases warrant further clinicopathologic studies.

Other clinical features seen to varying degrees in PSP include dysarthria and dysphagia. Aphasia is rare or absent in PSP, but much more common in CBD. Some degree of mental dysfunction is the rule in PSP, although severe dementia is not usual. Attention is impaired and cognitive processing is slowed [25]. Frontal lobe dysfunction may be prominent [1,38, $57,59]$. Cognitive impairment is not universal in CBD, but more frequent than in PSP. It also has features of a frontal lobe dementia marked by personality change, disorder of conduct, impaired attention and distractibility. Frontal lobe signs, including grasp reflex, forced groping, utilization behavior and intermanual conflict, characteristically are unilateral at onset and markedly asymmetric in CBD. In contrast, asymmetry is unusual in PSP.
The alien limb phenomenon, which describes involuntary movement, such as elevation of the arm or leg into the air, is often emphasized in CBD, but it is neither specific to CBD nor found in many cases. Cortical sensory deficits due to parietal lobe involvement and characterized by graphesthesia and astereognosis are frequent in CBD, but decidedly uncommon in PSP, which largely spares posterior cortical regions.

\section{Imaging studies in differentiation of PSP and CBD}

Imaging studies are of limited use in the diagnosis of PSP. Narrowing of the anteroposterior midbrain diameter and dilation of the third ventricle are characteristic [37]. Structural imaging is more informative in CBD, where magnetic resonance imaging often shows asymmetrical atrophy of the superior parietal lobule variably extending into frontal regions, especially the superior frontal cortex.

SPECT and PET scanning show bilateral frontal hypoactivity in PSP [17, 30, 55]. The hallmark finding of such studies in CBD is asymmetry of hypometabolism in superior frontal and parietal lobes [6, 70]. Hypometabolism is sometimes also detected in caudate, putamen or thalamus in CBD. PET scans assessing dopamine metabolism $\left[{ }^{18} \mathrm{~F}\right]$-DOPA may show reduction of striatal and medial frontal uptake [70]. Striatal uptake is usually most severely impaired contralateral to the clinically most affected limbs. Symmetrical striatal dopaminergic deficits are found in PSP [5, 9].

\section{Neuropathology of PSP}

While the majority of clinically well-characterized patients with PSP have distinctive postmortem findings, there have been several reports suggesting that the match is not always perfect $[13,19,33]$. Gross examination of the brain may be unrevealing in PSP, but the most common pathological findings are midbrain atrophy, with dilation of the aqueduct of Sylvius and depigmentation of the substantia nigra. The locus ceruleus less often shows decreased pigment. The subthalamic nucleus may be noticeably smaller than expected and the superior cerebellar peduncle may be small. The external examination of the cerebral cortex may be normal, but mild atrophy in the frontal lobes, extending to the pre-central gyrus is not uncommon.

Microscopic findings include neuronal loss, fibrillary gliosis and NFT in basal ganglia, diencephalon and brainstem. A characteristic distribution is generally observed (Table 1) [28, $34,40,51]$. The substantia nigra, globus pallidus and subthalamic nucleus are involved and demonstrate marked neuronal loss and reactive gliosis. The globus pallidus shows neuronal loss, gliosis, and NFT as well as iron pigment deposits and 
Table 1 Neuropathologic differentiation of PSP and CBD

\begin{tabular}{|c|c|c|}
\hline & PSP & CBD \\
\hline Gross atrophy & $\begin{array}{l}\text { Frontal, parasagittal } \\
\text { or paracentral }\end{array}$ & $\begin{array}{l}\text { Lobar (asymmetric, } \\
\text { frontoparietal or } \\
\text { paracentral) }\end{array}$ \\
\hline Ballooned neurons & $\begin{array}{l}\text { Rare (limited to limbic } \\
\text { lobe) }\end{array}$ & $\begin{array}{l}\text { Numerous in } \\
\text { affected neocortical } \\
\text { areas \& limbic lobe }\end{array}$ \\
\hline NFT & $\begin{array}{l}\text { Globose \& flame shaped } \\
\text { Striatum } \\
\text { Globus pallidus } \\
\text { Basal nucleus } \\
\text { Subthalamic nucleus } \\
\text { Substantia nigra } \\
\text { Oculomotor nuclei } \\
\text { Raphe nuclei } \\
\text { Locus ceruleus } \\
\text { Pontine nucleus } \\
\text { Tegmental gray } \\
\text { Inferior olive }\end{array}$ & $\begin{array}{l}\text { Mostly globose } \\
\text { (so-called } \\
\text { corticobasal bodies) } \\
\text { Substantia nigra } \\
\text { Locus ceruleus } \\
\text { Raphe nuclei }\end{array}$ \\
\hline $\begin{array}{l}\text { Pick body-like } \\
\text { tau inclusions }\end{array}$ & Dentate fascia & $\begin{array}{l}\text { Cortex (layers II } \\
\text { and III) }\end{array}$ \\
\hline Neuropil threads & $\begin{array}{l}\text { Present (sparse to many) } \\
\text { Basal ganglia } \\
\text { Internal capsule } \\
\text { Thalamic fasciculus }\end{array}$ & $\begin{array}{l}\text { Present (usually } \\
\text { numerous) } \\
\text { Cortex } \\
\text { Cerebral white } \\
\text { matter } \\
\text { Internal capsule } \\
\text { Pencil fibers in } \\
\text { striatum } \\
\text { Thalamic fasciculus } \\
\text { Cerebral peduncle } \\
\text { Tegmental fibers } \\
\text { Pontine fibers }\end{array}$ \\
\hline Glial lesions & $\begin{array}{l}\text { Tufted astrocytes } \\
\text { Coiled bodies } \\
\text { (oligodendroglial) }\end{array}$ & $\begin{array}{l}\text { Astrocytic plaques } \\
\text { Coiled bodies } \\
\text { (oligodendroglial) }\end{array}$ \\
\hline Other pathology & $\begin{array}{l}\text { Grumose degeneration of } \\
\text { cerebellar dentate nucleus }\end{array}$ & $\begin{array}{l}\text { Corticospinal tract } \\
\text { degeneration }\end{array}$ \\
\hline
\end{tabular}

granular neuroaxonal spheroids. The striatum and thalamus, especially ventral anterior and ventrolateral nuclei, are also affected. The nucleus basalis of Meynert usually has mild cell loss, but more noticeable neurofibrillary pathology. The brainstem regions that are usually affected include the superior colliculus, periaqueductal gray matter, oculomotor nuclei, locus ceruleus, pontine nuclei, pontine tegmentum, vestibular nuclei and inferior olives. The cerebellar dentate nucleus is also frequently affected and may show grumose degeneration $[2,16,60]$. Spinal cord involvement is common although it is often not routinely studied [57].
Neuronal loss is usually greatest in the ventrolateral tier of the substantia nigra, as in PD [44], but there is often more extensive neuronal loss throughout all regions of the substantia nigra [50]. Neuronal cell loss is accompanied by fibrillary gliosis and globose-shaped NFT. Neuronal loss and NFT may be prominent in the globus pallidus. Large striatal neurons appear especially vulnerable, and loss of up to 30 to $40 \%$ of these cells has been reported [63]. Neuronal loss in the basal nucleus of Meynert ranges from 13 to $54 \%$ [77].

Cortical pathology is less pronounced, but frequent in the motor and pre-motor cortices [41, 42, 48, 81]. Early studies emphasized the lack of neocortical pathology in PSP [76], but more recent studies indicate consistent involvement of the frontal cortex in PSP $[8,41,42,81]$. Neocortical NFT and glial tangles are concentrated in the precentral gyrus [41, 42].

Neurofibrillary pathology in the hippocampus is variable in PSP and not apparently intrinsic to the disorder, but rather more consistent with concurrent age-related pathology [8]. When present, the distribution of NFT in the hippocampal formation is qualitatively similar to that of AD. The exception to this rule is the frequent involvement of the dentate granule cells in PSP [42]. The degree of neurofibrillary degeneration may correlate with degree of cognitive impairment in PSP as in aging and $\mathrm{AD}$ [7].

While NFT in PSP often have a rounded or globose appearance, flame-shaped NFT are also detected. The Gallyas silver iodine method is sensitive to pathological structures in PSP and it demonstrates, in addition to NFTs, fibrillary inclusions in glial cells and cell processes. As in AD, NFT in PSP contain abnormally phosphorylated tau protein $[27,39$, 47]. Immunocytochemistry for tau protein specifically demonstrates NFT in PSP, but also a wide variety of inclusions in both neurons and glia, including neuropil threads and tufts of abnormal fibers. The latter structures have been shown to be tau inclusions in astrocytes $[49,62,84,85]$. Tufted astrocytes have a predilection for the frontal cortex areas and striatum and are often abundant in the precentral gyrus. Glial pathology accounts for much of the cortical pathology observed in PSP.

Tau immunohistochemistry also reveals tau-positive fibers $[46,66]$ and small round cells in the white matter of areas affected by PSP. The tau-positive cells in white matter, also referred to as "coiled bodies", have been shown to be oligodendroglial inclusions [26, 49]. Some of the thread-like processes in white matter have been shown to be within both axons and the outer mesaxon of myelinated fibers. In gray matter tau-positive processes are much less common in PSP than in $\mathrm{AD}$ [18].

The NFT in PSP may be distinguished from NFT in AD by the paucity of ubiquitin immunoreactivity $[4,15]$. Certain neurofilament epitopes may also distinguish NFT in PSP from those in AD [72]. A recent study with a panel of anti-tau antibodies recognizing epitopes along the length of the tau mole- 
cule suggested that full length tau proteins are incorporated into the lesions in both AD and PSP [71].

\section{Neuropathology of CBD}

The gross examination of the brain usually shows narrowing of cortical gyri, most marked in pre- and post-central regions associated with widening of sulci, of greatest severity contralateral to the side of motor onset. This superior frontoparietal atrophy merges with less severe atrophy in anterior frontal and posterior parietal regions, while the temporal and occipital cortical regions are relatively preserved. The brainstem and cerebellum are not consistently reduced in size, but horizontal sectioning of the brainstem shows loss of pigment in the substantia nigra and mild atrophy of the midbrain tegmentum with enlargement of the aqueduct.

In affected areas, especially the superior frontal gyrus, swollen and vacuolated cortical neurons, referred to as ballooned neurons (BN), are scattered in the third, fifth and sixth cortical layers. BN may be found in large numbers in anterior cingulate, amygdala and claustrum; and in smaller numbers in posterior cingulate, temporal, insular, parietal and frontal cortex. They are much less frequently found in striatum, thalamus and hippocampus and have not been reported in calcarine cortex or cerebellum. BN are eosinophilic and weakly argyrophilic, and they lack apparent Nissl substance. They often have swollen proximal dendrites. Some are vacuolated, and granulovacuolar bodies may be found in BN. Rebeiz and colleagues called this appearance neuronal achromasia, a term which they extended to cover subcortical swollen cells, and to nigral and brainstem neurons with illdefined inclusions. The BN are analogous to "Pick cells" in Pick's disease [23]. BN are strongly immunoreactive for phosphorylated neurofilaments $[24,73]$ and variably reactive for tau protein. $\mathrm{BN}$ also show reactivity for $\alpha \mathrm{B}$-crystallin [58], and sometimes for ubiquitin and tau [26,73], but not for epitopes specific to neurofibrillary tangles [24]. Ultrastructurally, the cytoplasm of the ballooned neurons contains rather disorderly accumulations of filaments $9-16 \mathrm{~nm}$ in diameter, interspersed with other cytoplasmic elements [12].

On microscopic examination, sections of atrophic frontoparietal cortex show moderately severe nerve cell loss and subcortical myelin pallor with gliosis. There is disruption of the normal pattern of cortical lamination, superficial spongiosis and diffuse astrocytic and microglial proliferation. Atrophic cortical areas consistently contain scattered argyrophilic neuronal inclusions in the second and third layers, which are similar to pleomorphic Pick bodies or small NFT [26, 52]. The neuronal inclusions in CBD differ from Pick bodies in that they are more fibrillar, not always round and less well circumscribed. Pick bodies are abundant in the granule cell layer of the dentate gyrus of the hippocampus, an area relatively unaffected in CBD. As in PSP, affected white matter has taupositive cell processes and oligodendroglial inclusions, but they are more numerous and widespread in CBD than in PSP. In contrast to $\mathrm{AD}$, where tau positive processes are limited to gray matter, in CBD the white matter also is severely affected.

The substantia nigra usually shows moderate to severe nerve cell loss with extraneuronal neuromelanin and gliosis. Many of the remaining neurons contain ill-defined neurofibrillary inclusions, so-called "corticobasal bodies" [35]. These inclusions have a homogeneous or whorled appearance and granules of melanin tend to become enmeshed in some of them. They are essentially indistinguishable from globose tangles of PSP. The locus ceruleus and raphe nuclei have similar inclusions. In contrast to PSP where neurons in the pontine base almost always have at least a few NFT, the pontine base is largely free of NFT in CBD. On the other hand, tau inclusions in glia and in cell processes are frequent in the pontine base in CBD. NFT are also detected in the tegmental gray matter.

In other subcortical regions the globus pallidus and putamen show nerve cell depletion with gliosis and occasional NFT. The nucleus basalis of Meynert has a few NFT. The red nucleus and subthalamic nucleus also show mild neuronal depletion and astrocytic gliosis and may have NFT. Thalamic nuclei may also be affected, particularly the ventrolateral nucleus. Mild neuronal depletion of the dentate nucleus occurs, but grumose degeneration is much less common than in PSP.

The Gallyas silver stain is a sensitive way of demonstrating pathology in neurons and glia in CBD [43]. With this technique the tangles vary from wispy fragments to densely silver impregnated inclusions. Immunocytochemistry with monoclonal antibodies shows that many inclusions have positive reactions to epitopes in phosphorylated neurofilaments and tau $[61,64,82]$. The glial lesions in PSP and CBD are distinctive as seen in these sections stained with the Gallyas method. Glial inclusions in neurodegenerative disorders have been the subject of a recent review [11]. The characteristic pathology in CBD is in cell processes - distal cellular domains - while in PSP it is in cell bodies - proximal cellular domains [26]. The abnormal astrocytic lesions in CBD are characterized by stubby tau-positive processes radially arranged around a central astrocyte. Because the lesions are reminiscent of neuritic plaques in $\mathrm{AD}$, but they lack amyloid, they are referred to as astrocytic plaques [26]. The abnormal astrocytes in PSP appear as irregular fibrous tufts and have been referred to as tufted astrocytes [22].

\section{Ultrastructural differences between PSP and CBD}

While NFT in AD are composed mostly of 22-nm diameter paired helical filaments (PHF) and a minor component of 15- 
to 18-nm diameter straight filaments [79], similar studies of NFT in PSP show mostly straight filaments $[10,65,69,78,83]$. In addition astrocytes in PSP contain straight filaments [62]. In CBD the filaments, like those in $\mathrm{AD}$, have a paired helical appearance, but the diameter is wider and the periodicity is longer. These structures have been referred to as twisted ribbons. Studies of their mass per unit length also show differences in the filaments in CBD compared to $\mathrm{AD}$ [53].

\section{Molecular biology of tau protein in CBD and PSP}

Biochemical methods distinguish the tau protein abnormalities in AD from PSP. Western blots of detergent-insoluble tau, which is a pathologic form of tau not detected in normal brains, from $\mathrm{AD}$ brain reveal three tau-immunoreactive bands of 60 , 64 , and $68 \mathrm{kD}$. In contrast, similar detergent insoluble proteins from PSP shows a characteristic doublet of 64 and $68 \mathrm{kd}[29$, 81]. Interestingly, the entorhinal cortex of PSP brains contained not the doublet characteristic of PSP, but the triplet found in $\mathrm{AD}$ material. These results support the suggestion that allocortical pathology in PSP is similar to that in AD. After dephosphorylation, the pathologic tau proteins in PSP are composed almost exclusively of tau with four repeats with respect to the conserved repeats in the carboxyl half of the molecular that form the microtubule-binding site. In contrast, the pathologic tau protein from $\mathrm{AD}$ has both three and four repeat isoforms.

Biochemical studies of tau protein in CBD are few, but it also is a disorder characterized by two major tau isoforms, as in PSP [53]. While initial studies suggested that the doublet in PSP was different from the doublet in CBD, more recent studies using dephosphorylation shows that pathologic tau protein in CBD, like PSP, is composed of four repeat tau [75]. Given the fact that the major difference between three and four

Fig. 1 Tau immunostaining of cerebral cortex and white matter in a case of CBD and another of PSP. Note the presence of numerous thread-like processes in both the gray and white matter in CBD. In contrast, PSP has fewer threads and more inclusions in cell bodies of neurons and glia. A prominent tufted astrocyte in the gray matter and several coiled bodies are readily apparent in PSP.
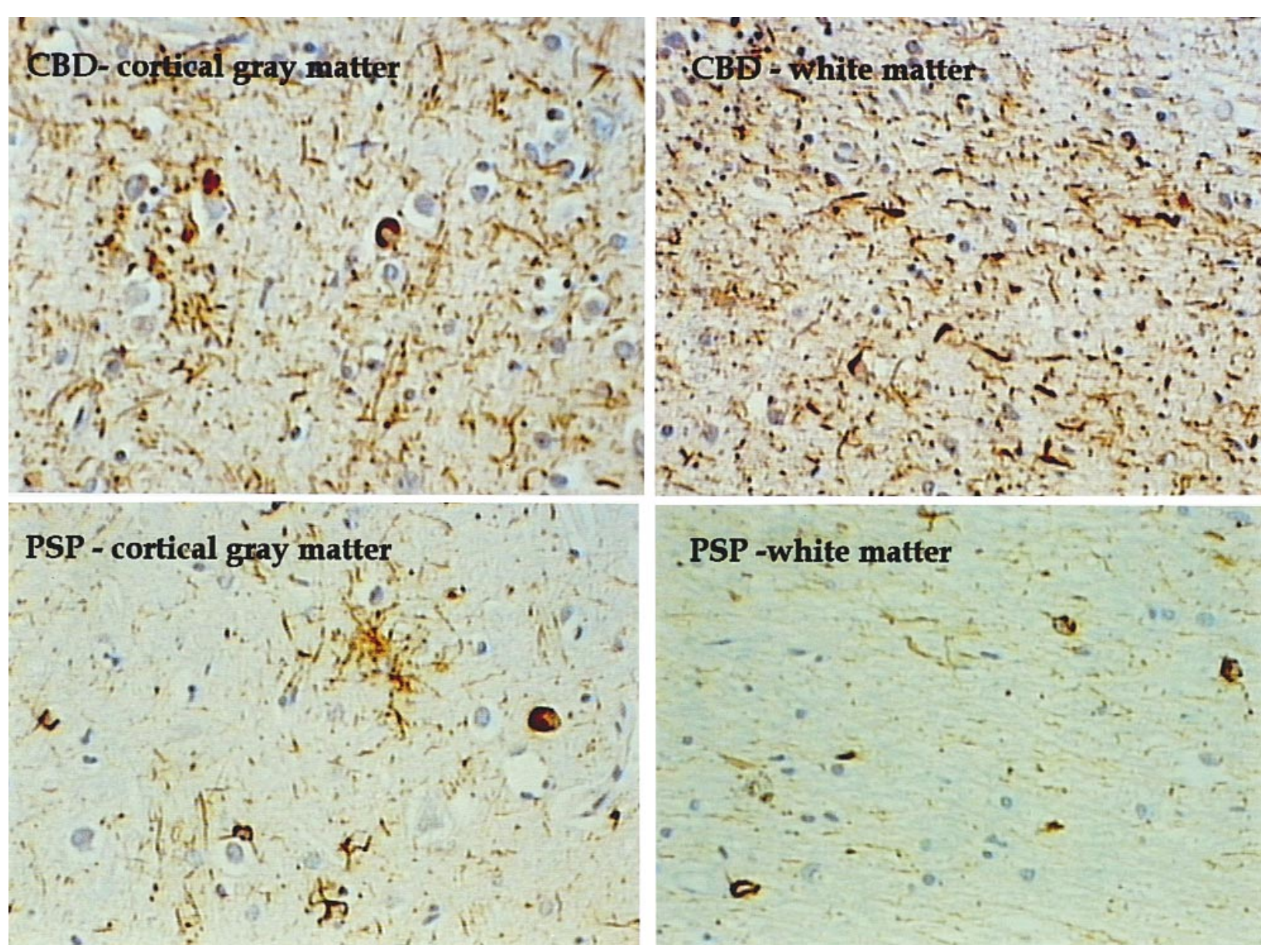
repeat tau is alternative splicing of exon 10 , these observations are of interest. Several of the mutations in tau in FTDP-17 specifically affect alternative splicing of exon 10 [45]. Thus, PSP and CBD, which are mostly sporadic disorders, may share similar mechanisms of pathogenesis with respect to abnormal tau isoforms. Further studies of the pathogenesis of these welldefined genetic diseases may shed light on the more common sporadic diseases.

\section{Etiology of PSP and CBD}

The etiology of PSP is unknown, but as in many neurodegenerative diseases a multifactorial causation is implicated. Genetic influences are increasingly suggested. Although there are only a few reports of autopsy-proven familial PSP [21, 32, 80], recent studies have revealed a genetic polymorphism in the tau gene associated with greater than chance frequency with PSP [14]. The initial observation of a single polymorphism in tau in PSP has been confirmed in several studies and more recently the initial observations have been discovered to reflect an extended haplotype of the tau gene [3]. Essentially two forms of the tau gene have been defined - $\mathrm{H} 1$ and $\mathrm{H} 2$. Most cases of typical PSP are $\mathrm{H} 1$ and a surprising large number of PSP patients are H1/H1 homozygous. There is some preliminary evidence to suggest greater variability in the disease phenotype in PSP cases that are heterozygous (H1/ H2). CBD also appears to be associated with increased frequency of $\mathrm{H} 1$ haplotype, but this observation is based upon a much smaller sample size.

Almost all reported cases of CBD have been sporadic, but there are rare familial reports of CBD. In addition the frontotemporal dementia with Parkinsonism linked to chromosome 17 (FTDP-17) shares a number of pathologic features with

Fig. 2 Sections of the subthalamic nucleus of Luys in a case of CBD (top row) and PSP (bottom row) stained with H\&E (left) and tau (right). The neurons are preserved in the subthalamic nucleus of CBD, but there is marked neuronal loss and dense fibrillary gliosis in PSP. A residual neurons in the PSP case have a globose NFT. More numerous NFT are visible with tau immunostaining. In $\mathrm{CBD}$, tau immunostaining reveals thread-like processes and punctate to finely fibrillary inclusions in small neurons.
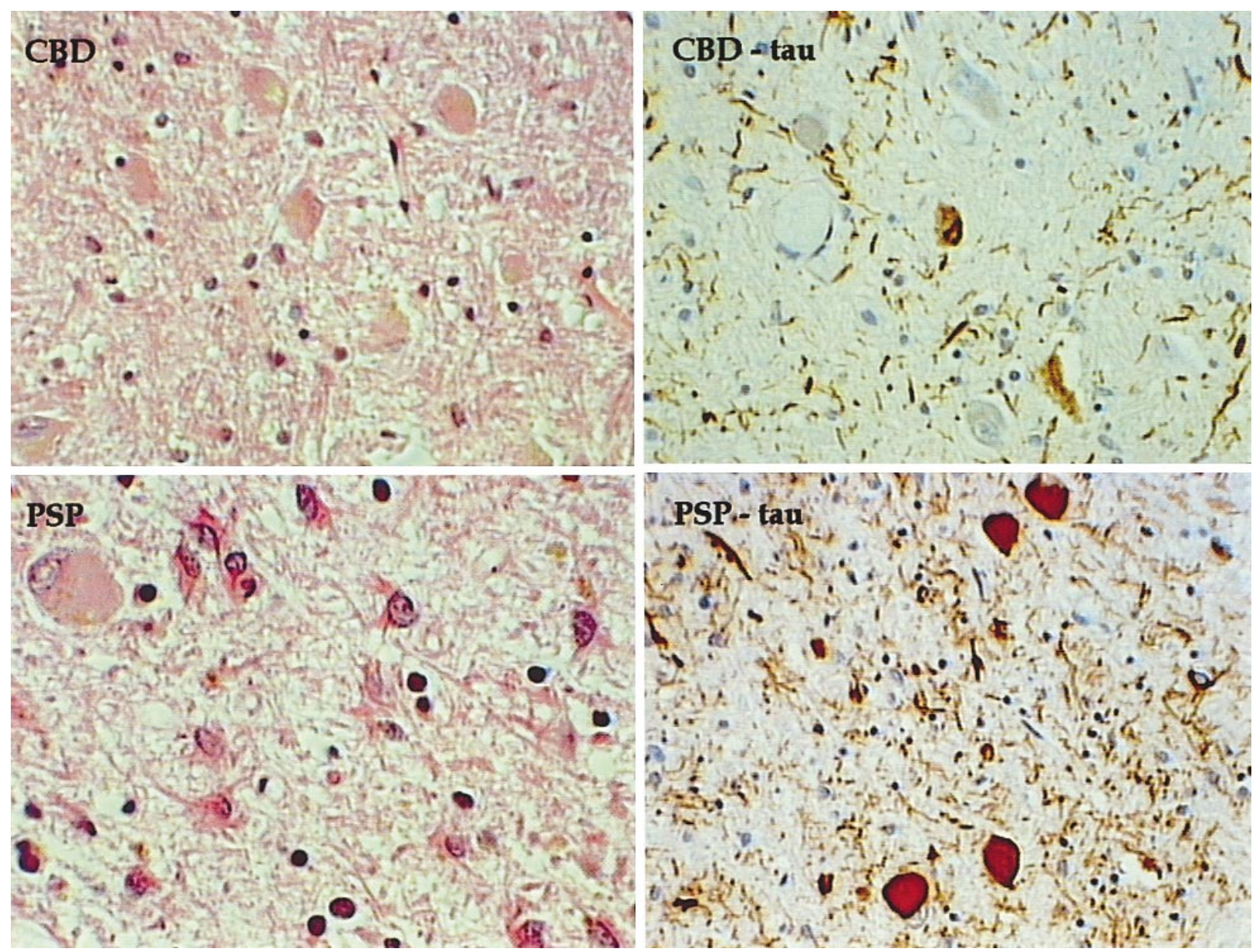
PSP and CBD. In particular, familial multi-system tauopathy reported by Ghetti and familial pedunculopontine degeneration have many histological, ultrastructural and biochemical similarities [74]. These disorders are clearly linked to a gene on chromosome 17 [31], and recent studies have implicated tau as the gene. In particular, mutations in the coding and noncoding regions of the tau gene have been identified in some families with FTDP-17 [45].

Environmental factors are suspected to play a role in the causation of PSP, but a case-control study has failed to identify a factor or factors that might be responsible. In particular, pesticide exposure, well-water use, nonsmoking and head trauma were not associated with increased risk of PSP [20,37]. Comparable case-control studies of environmental factors have not been conducted for CBD.

\section{Differential diagnosis}

While there is considerable overlap in the pathology in PSP and CBD. The two disorders can usually be readily distinguished. In CBD the brunt of the defining pathology is in the cortex and cortical white matter (Fig. 1). BN are nearly a sine qua non for CBD, but are quite uncommon in PSP, except in the limbic gray matter, where $\mathrm{BN}$ can be found in a number of degenerative disorders, including AD. While there is no disputing the fact that cortical pathology is found in PSP, the brunt of the pathology of PSP is subcortical, with particularly severe disease in the pallido-Luysial-nigral axis (Fig. 2). In PSP, tau is prominent in cell bodies in neurons and oligodendroglia, and astrocytes in the cortex and striatum. In CBD, tau is most abundant in cell processes (Fig. 3). Table 1 summarizes the major differences.

Acknowledgment Supported by the Eloise H. Troxel Memorial Fund for PSP Research.
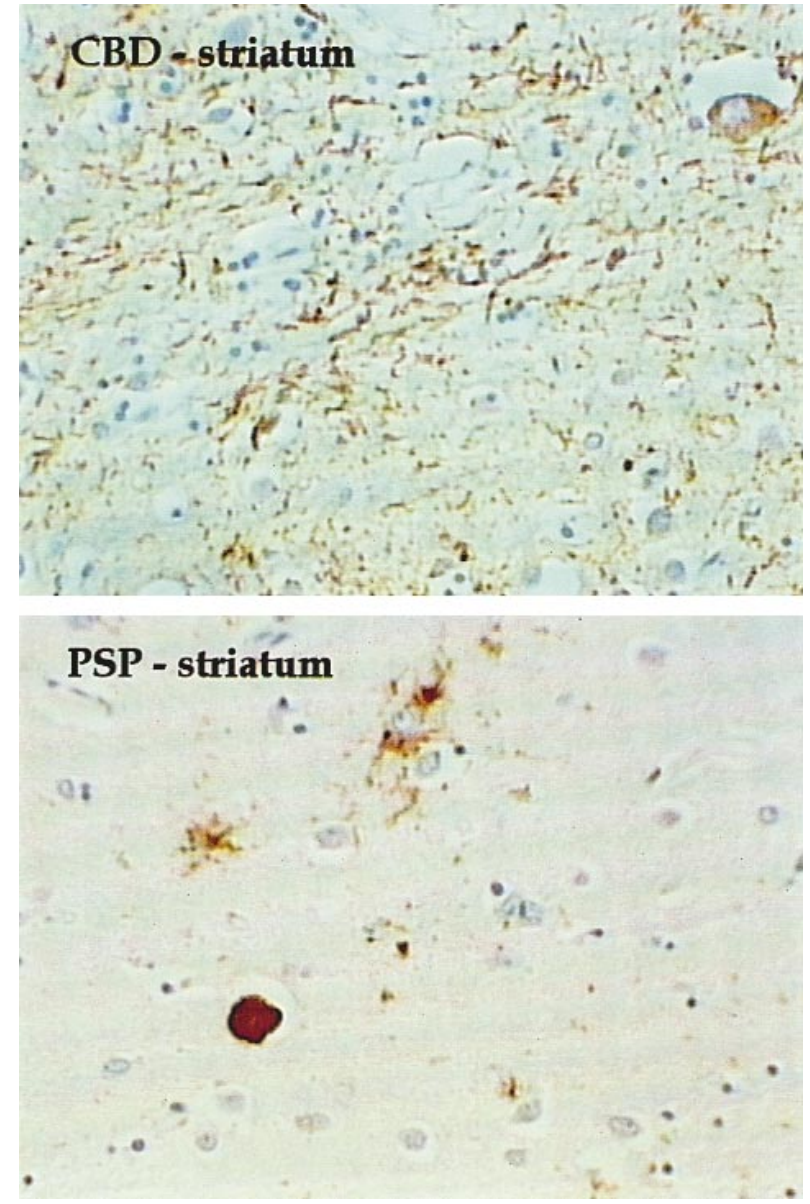

Fig. 3 The corpus striatum in CBD and PSP present different pathologies. In CBD the predominant finding on tau immunostained sections is numerous thread-like processes in gray and white matter, especially in the pencil fibers. In contrast globose NFT and tufted astrocytes are found in PSP with only sparse thread-like processes. 


\section{References}

1. Agid Y, Javoy-Agid F, Ruberg M, Pillon B, Dubois B, Duyckaerts C, Hauw JJ, Baron JC, Scatton B (1987) Progressive supranuclear palsy: anatomoclinical and biochemical considerations. Adv Neurol 45: 191-206

2. Arai N (1987) "Grumose degeneration" of the dentate nucleus. A light and electron microscopic study in PSP and dentatorubropallidoluysian atrophy. J Neurol Sci 90: 131-145

3. Baker M, Litvan I, Houlden H, Adamson J, Dickson D, Perez-Tur J, Hardy J, Lynch T, Bigio E, Hutton M (1999) Association of an extended haplotype in the tau gene with progressive supranuclear palsy. Human Mol Gen 8: 711-715

4. Bancher C, Lassmann H, Budka H, Grundke-Iqbal I, Iqbal K, Wiche G, Seitelberger F, Wisniewski HM (1987) Neurofibrillary tangles in Alzheimer's disease and progressive supranuclear palsy: Antigenic similarities and differences. Acta Neuropathol 74: 39-46

5. Baron JC, Maziere B, Loch C, Cambon H, Sgouropoulos P, Bonnet AM, Agid Y (1986) Loss of striatal $\left[{ }^{76} \mathrm{Br}\right]$ bromospiperone binding sites demonstrated by positron tomography in progressive supranuclear palsy. J Cerebral Blood Flow Metab 6: 131-136

6. Blin J, Vidailhet M-J, Pillon B, Dubois B, Feve J-R, Agid Y (1992) Corticobasal degeneration: decreased and asymmetrical glucose consumption as studied with PET. Movement Disorders 7: 348-354

7. Braak H, Braak E (1991) Neuropathological stageing of Alzheimer-related changes. Acta Neuropathol 82: 239-259

8. Braak H, Jellinger K, Braak E, Bohl J (1992) Allocortical neurofibrillary changes in progressive supranuclear palsy. Acta Neuropathol 84: 478-483

9. Brooks DJ, Ibanez V, Sawle GV, Quinn N, Lees AJ, Mathias CJ, Bannister R, Marsden CD, Frakowiak RSJ (1990) Differing patterns of striatal ${ }^{18} \mathrm{~F}$-dopa uptake in Parkinson's disease multiple system atrophy and progressive supranuclear palsy. Ann Neurol 28: 547-555

10. Bugiani O, Mancardi GL, Brusa A, Ederli A (1979) The fine structure of subcortical neurofibrillary tangles in progressive supranuclear palsy. Acta Neuropathol 45: 147-152
11. Chin SS, Goldman JE (1996) Glial inclusions in CNS degenerative diseases. J Neuropathol Exp Neurol 55: 499-508

12. Clark AW, Manz HJ, White CL $3^{\text {rd }}$, Lehmann J, Miller D, Coyle JT (1986) Cortical degeneration with swollen chromatolytic neurons: its relationship to Pick's disease, J Neuropathol Exp Neurol 45: 268-284

13. Collins SJ, Ahlskog JE, Parisi JE, Maraganore DM (1995) Progressive supranuclear palsy: neuropathologically based diagnostic clinical criteria. J Neurol Neurosurg Psychiatry 58: 167-173

14. Conrad C, Andreadis A, Trojanowski JQ, Dickson DW, Kang D, Chen X, Wiederholt W, Hansen L, Masliah E, Thal LJ, Katzman R, Xia Y, Saitoh T (1997) Genetic evidence for the involvement of $\tau$ in progressive supranuclear palsy. Ann Neurol 41: 277 281

15. Cruz-Sanchez FF, Rossi ML, Cardozo A, Deacon P, Tolosa E (1992) Clinical and pathological study of two patients with progressive supranuclear palsy and Alzheimer's changes. Antigenic determinants that distinguish cortical and subcortical neurofibrillary tangles. Neurosci Lett 136: 43-46

16. Cruz-Sanchez FF, Rossi ML, Cardozo A, Picardo A, Tolosa E (1992) Immunohistological study of grumose degeneration of the dentate nucleus in progressive supranuclear palsy. J Neurological Sci 110: 228 231

17. D'Antona R, Baron JC, Sanson Y, Serdaru M, Viader F, Agid Y, Cambier J (1985) Subcortical dementia: frontal cortex hypometabolism detected by positron tomography in patients with progressive supranuclear palsy. Brain 108: 785-799

18. Davis DG, Wang HZ, Markesbery WR (1992) Image analysis of neuropil threads in Alzheimer's Pick's diffuse Lewy body disease and in progressive supranuclear palsy. J Neuropathol Exp Neurol 51: 594600

19. Davis PH, Bergeron C, McLachlan R (1985) Atypical presentation of progressive supranuclear palsy. Ann Neurol 17: $337-$ 343

20. Davis PH, Golbe LI, Duvoisin RC, Schoenberg BS (1988) Risk factors for progressive supranuclear palsy. Neurology 38: 15461552

21. de Yébenes YG, Sarasa JL, Daniel SE, Lees AJ (1995) Familial progressive supranuclear palsy: description of a pedigree and review of the literature. Brain 118: 10951103
22. Dickson DW (1997) Neurodegenerative diseases with cytoskeletal pathology: a biochemical classification. Ann Neurol 42: 541-544

23. Dickson DW (1998) Pick's disease: a modern approach. Brain Pathol 8: 339-354

24. Dickson DW, Yen S-H, Suzuki KI, Davies P, Garcia JH, Hirano A (1986) Ballooned neurons in select neurodegenerative diseases contain phosphorylated neurofilament epitopes. Acta Neuropathol 71: 216-23

25. Dubois B, Pillon B, Legault F, Agid Y, Lhermitte F (1988) Slowing of cognitive processing progressive supranuclear palsy: a comparison with Parkinson's disease. Arch Neurol 45: 1194-1199

26. Feany MB, Dickson DW (1995) Astrocytic plaques and widespread cytoskeletal pathology characterize corticobasal degeneration. Am J Pathol 146: 1388-1396

27. Feany MB, Ksiezak-Reding H, Liu W-K, Vincent I, Yen S-H, Dickson DW (1995) Epitope expression and hyperphosphorylation of tau protein in corticobasal degeneration: differentiation from progressive supranuclear palsy. Acta Neuropathol 90: 37-43

28. Feany MB, Mattiace LA, Dickson DW (1996) Neuropathologic overlap of progressive supranuclear palsy Pick's disease and corticobasal degeneration. J Neuropathol Exp Neurol 55: 53-67

29. Flament S, Delacourte A, Verny M, Hauw J-J, Javoy-Agid F (1991) Abnormal tau proteins in progressive supranuclear palsy. Acta Neuropathol 81: 591-596

30. Foster NL, Gilman S, Berent S, Morin EM, Brown MB, Koeppe RA (1988) Cerebral hypometabolism in progressive supranuclear palsy studied with positron emission tomography. Ann Neurol 24: 399-406

31. Foster NL, Wilhelmsen K, Sima AAF, Jones MZ, D'Amato CJ, Gilman S, Conference Participants (1997) Frontotemporal dementia and parkinsonism linked to chromosome 17: A consensus conference. Ann Neurol 41: 706-715

32. Gazeley S, Maguire JA (1996) Familial progressive supranuclear palsy. Clin Neuropathol 15: 215-220 
33. Gearing M, Olson DA, Watts RL, Mirra SS (1994) Progressive supranuclear palsy: Neuropathologic and clinical heterogeneity. Neurology 44: 1015-1024

34. Geddes JF, Hughes AJ, Lees AJ, Daniel SE (1993) Pathological overlap in cases of parkinsonism associated with neurofibrillary tangles. Brain 116: 281-302

35. Gibb WRG, Luthert PJ, Marsden CD (1989) Corticobasal degeneration. Brain 112: $1171-1192$

36. Golbe LI, Davis PH, Schoenberg BS, Duvoisin RC (1988) Prevalence and natural history of progressive supranuclear palsy. Neurology 38: 1031-1034

37. Golbe LI (1993) Progressive supranuclear palsy. In: Stern MB, Koller WC (eds) Parkinsonian Syndromes. Marcel Dekker, New York, pp 227-247

38. Grafman J, Litvan I, Gomez C, Chase TN (1990) Frontal lobe function in progressive supranuclear palsy. Arch Neurol 47: 553-558

39. Greenberg SC, Davies P (1990) A preparation of Alzheimer paired helical filaments that displays distinct tau proteins by polyacrylamide gel electrophoresis, Proc Natl Acad Sci (USA) 87: 5827-5831

40. Hauw J-J, Daniel SE, Dickson D, Horoupian DS, Jellinger K, Lantos PL, McKee A, Tabaton M, Litvan I (1994) Preliminary NINDS neuropathologic criteria for SteeleRichardson-Olszewski syndrome (progressive supranuclear palsy). Neurology 44 : 2015-2019

41. Hauw J-J, Verny M, Delaere P, Cervera P, He Y, Duyckaerts C (1990) Constant neurofibrillary changes in the neocortex in progressive supranuclear palsy: Basic differences with Alzheimer's disease and aging. Neurosci Lett 119: 182-186

42. Hof PR, Delacourte A, Bouras C (1992) Distribution of cortical neurofibrillary tangles in progressive supranuclear palsy: A quantitative analysis of six cases. Acta Neuropathol 84: 45-51

43. Horoupian DS, Chu PL (1994) Unusual case of corticobasal degeneration with tau/Gallyas-positive neuronal and glial tangles. Acta Neuropathol 88: 592-598

44. Hughes AJ, Daniel SE, Blankson S, Lees AJ (1993) A clincopathologic study of 100 cases of Parkinson's disease. Arch Neurol 50: $140-148$
45. Hutton M, Lendon CL, Rizzu P, Baker M, Froelich S, Houlden H, Pickering-Brown S, Chakraverty S, Isaacs A, Grover A, Hackett J, Abramson J, Lincoln S, Dickson D, Davies P, Petersen RC, Stevens M, de Graaf E, Wauters E, van Baren J, Hillebrand M, Joosen M, Kwon J, Nowotny J, Che LK, Norton J, Morris JC, Reed LA, Trojanowski J, Basun H, Lannfelt L, Neystat M, Fahn S, Dark F, Tannenberg T, Dodd PR, Hayward N, Kwok JBJ, Schofield PR, Andreadis A, Snowden J, Crauford D, Neary D, Owen F, Oostra BA, Hardy J, Goate A, van Swieten J, Mann D, Lynch T, Heutink P (1998) Association of missense and 5'-splice-site mutations in tau with the inherited dementia (FTDP-17). Nature 393: 702-705

46. Ikeda K Akiyama H, Haga C, Kondo H, Arima K, Oda T (1994) Argyrophilic thread-like structure in corticobasal degeneration and supranuclear palsy. Neurosci Lett 174: 157-159

47. Iqbal K, Grundke-Iqbal I, Smith AJ, George L, Tung Y-C, Zaidi T (1989) Identification and localization of tau peptide to paired helical filaments of Alzheimer disease. Proc Natl Acad Sci (USA) 86: 5646-5650

48. Ishino H, Otsuki S (1976) Frequency of Alzheimer's neurofibrillary tangles in the cerebral cortex in progressive supranuclear palsy (subcortical argyrophilic dystrophy). J Neurol Sci 28: 309-316

49. Iwatsubo T, Hasegawa M, Ihara Y (1994) Neuronal and glial tau-positive inclusions in diverse neurologic diseases share common phosphorylation characteristics. Acta Neuropathol 88: 129-136

50. Jellinger K (1971) Progressive supranuclear palsy (subcortical argyrophilic dystrophy). Acta Neuropathol 19: 347-352

51. Jellinger KA, Bancher C (1992) Neuropathology. In: Litvan I, Agid Y (eds) Progressive Supranuclear Palsy: Clinical and Research Approaches. Oxford University Press, New York, pp 44-88

52. Jendroska K, Rossor MN, Mathias CJ, Daniel SE (1995) Morphological overlap between corticobasal degeneration and Pick's disease: a clinicopathological report. Movement Dis 10: 111-114

53. Ksiezak-Reding H, Morgan K, Mattiace LA, Davies P, Liu W-K, Yen S-H, Weidenheim KM, Dickson DW (1994) Ultrastructure and biochemical composition of paired helical filaments in corticobasal degeneration. Am J Pathol 145: 1496-1508

54. Lang AE, Riley DE, Bergeron C (1994) Cortical-basal ganglionic degeneration. In: Calne DB (ed) Neurodegenerative Diseases. WB Saunders, Philadelphia, pp $877-$ 894
55. Leenders KL, Frackowiak RSJ, Lees J (1988) Steele-Richardson-Olszewski syndrome: Brain energy metabolism blood flow and fluorodopa uptake measured by positron emission tomography. Brain 111: 615-630

56. Leiguarda R, Lees AJ, Merello M, Starkstein S, Marsden CD (1994) The nature of apraxia in corticobasal degeneration. J Neurol Neurosurg Psychiatry 57: 455-459

57. Litvan I, Grafman J, Gomez C, Chase TN (1989) Memory impairment in patients with progressive supranuclear palsy. Arch Neurol 46: 765-767

58. Lowe J, Errington DR, Lennox G, Pike I, Spendlove I, Landon M, Mayer RJ (1992) Ballooned neurons in several neurodegenerative diseases and stroke contain alpha $\mathrm{B}$ crystallin. Neuropathol Appl Neurobiol 18: 341-50

59. Maher ER, Smith EM, Lees AJ (1985) Cognitive deficits in the Steele-RichardsonOlszewski syndrome (progressive supranuclear palsy). J Neurol Neurosurg Psychiatry 48: 1234-1239

60. Mizusawa H, Yen S-H, Hirano A, Llena J (1989) Pathology of the dentate nucleus in progressive supranuclear palsy: a histological immunohistochemical and ultrastructural study. Acta Neuropathol 78: 419-428

61. Mori H, Nishimura M, Namba Y, Oda M (1994) Corticobasal degeneration: a disease with widespread appearance of abnormal tau and neurofibrillary tangles and its relation to progressive supranuclear palsy. Acta Neuropathol 88: 113-121

62. Nishimura M, Namba Y, Ideda K, Oda M (1992) Glial fibrillary tangles with straight tubules in the brains of patients with progressive supranuclear palsy. Neurosci Lett 143: 35-38

63. Oyanagi K, Takahashi H, Wakabayashi K, Ikuta F (1988) Large neurons in the neostriatum in Alzheimer's disease and progressive supranuclear palsy: a topographic, histologic and ultrastructural investigation. Brain Res 544 (2): 221-226

64. Paulus W, Selim M (1990) Corticonigral degeneration with neuronal achromasia and basal neurofibrillary tangles. Acta Neuropathol 81: 89-94

65. Powell HC, London GW, Lampert PW (1974) Neurofibrillary tangles in progressive supranuclear palsy: electron microscopic observations. J Neuropathol Exp Neurol 33: 98-106 
66. Probst A, Langui D, Lautenschlager C, Ulrich J, Brion JP, Anderton BH (1988) Progressive supranuclear palsy: extensive neuropil threads in addition to neurofibrillary tangles. Acta Neuropathol 77: 61-68

67. Rajput AH, Offord KP, Beard CM, Kurland LT (1984) Epidemiology of parkinsonism: Incidence classification and mortality. Ann Neurol 16: 278-282

68. Rebeiz JJ, Kolodny EH, Richardson EP (1968) Corticodentatonigral degeneration with neuronal achromasia. Arch Neurol 18: 20-33

69. Roy S, Datta CK, Hirano A, Ghatak NR, Zimmerman HM (1974) Electron microscopic study of neurofibrillary tangles in Steele-Richardson-Olszewski syndrome. Acta Neuropathol 29: 175-179

70. Sawle GV, Brooks DJ, Marsden CD, Frackowiak RSJ (1991) Corticobasal degeneration. A unique pattern of regional cortical oxygen hypometabolism and striatal fluorodopa uptake demonstrated by positron emission tomography. Brain 114: 541-556

71. Schmidt ML, Huang R, Martin JA, Henley J, Mawal-Dewan M, Hurtig HI, Lee VM, Trojanowski JQ (1996) Neurofibrillary tangles in progressive supranuclear palsy contain the same tau epitopes identified in Alzheimer's disease PHF-tau. J Neuropathol Exp Neurol 55: 534-539
72. Schmidt ML, Lee VM-Y, Hurtig H, Trojanowski JQ (1988) Properties of antigenic determinants that distinguish neurofibrillary tangles in progressive supranuclear palsy and Alzheimer's disease. 59: 460466

73. Smith TW, Lippa CF, de Girolami U (1992) Immunocytochemical study of ballooned neurons in cortical degeneration with neuronal achromasia. Clin Neuropathol 11: 28-35

74. Spillantini MG, Murrell JR, Goedert M, Farlow MR, Klug A, Ghetti B (1998) Mutation in the tau gene in familial multisystem tauopathy with presenile dementia. Proc Natl Acad Sci (USA) 95: 7737-7741

75. Spillantini MG, Bird TD, Ghetti B (1998) Frontotemporal dementia and Parkinsonism linked to chromosome 17: A new group of tauopathies. Brain Pathol 8: 387-402

76. Steele JC, Richardson JC, Olszewski J (1964) Progressive supranuclear palsy: a heterogenous degeneration involving the brain stem basal ganglia and cerebellum with vertical gaze and pseudobulbar palsy nuchal dystonia and dementia. Arch Neurol 10: 333-339

77. Tagliavini F, Pilleri G, Bouras C, Constantinidis J (1984) The basal nucleus of Meynert in patients with progressive supranuclear palsy. Neurosci Lett 44: $37-42$

78. Tellez-Nagel I, Wisniewski HM (1973) Ultrastructure of neurofibrillary tangles in Steele-Richardson-Olszewski syndrome. Arch Neurol 29: 324-327

79. Terry RD (1963) The fine structure of neurofibrillary tangles in Alzheimer's disease. J Neuropathol Exp Neurol 22: 629-642
80. Tetrud JW, Golbe LI, Forno LS, Farmer PM (1996) Autopsy-proven progressive supranuclear palsy in two siblings. Neurology 46: 931-934

81. Vermersch P, Robitaille Y, Berneir L, Wattez A, Gauvreau D, Delacourte A (1994) Biochemical mapping of neurofibrillary degeneration in a case of progressive supranuclear palsy: evidence for general cortical involvement. Acta Neuropathol 87: 572-577

82. Wakabayashi K, Oyanagi K, Makifuchi T, Ikuta F, Honna A, Honna Y, Horikawa Y, Tokiguche S (1994) Corticobasal degeneration: etiopathological significance of the cytoskeletal alterations. Acta Neuropathol 87: 545-553

83. Yagishita S, Itoh Y, Amano N, Nakano T, Saitoh A (1979) Ultrastructure of neurofibrillary tangles in progressive supranuclear palsy. Acta Neuropathol 48: 27-30

84. Yamada T, Calne DB, Akiyama H, McGeer EG, McGeer PL (1993) Further observations on tau-positive glia in the brains with progressive supranuclear palsy. Acta Neuropathol 85: 308-315

85. Yamada T, McGeer PL, McGeer EG (1992) Appearance of paired nucleated tau-positive glia in patients with progressive supranuclear palsy brain tissue. Neurosci Lett 135: 99-102 